\title{
Geriatric Physician
}

National Cancer Institute

\section{Source}

National Cancer Institute. Geriatric Physician. NCI Thesaurus. Code C157373.

A medical doctor who specializes in the diagnosis, treatment, and prevention of disease and disability in older adults. 